\title{
The substantiation of methodical instrumentation to increase the tempo of high-rise construction in region
}

\author{
Svetlana Belyaeva ${ }^{1, *}$, Tatyana Makeeva ${ }^{1}$, Andrei Chugunov ${ }^{1}$ and Peraskovya Andreeva ${ }^{2}$ \\ ${ }^{1}$ Voronezh State Technical University, Moscow Avenue, 14, Voronezh, 394026, Russia \\ ${ }^{2}$ Moscow State University of Civil Engineering, Yaroslavskoye shosse 26, Moscow, 129337, Russia
}

\begin{abstract}
One of the important conditions of effective renovation of accommodation in region on the base of realization of high-rise construction projects is attraction of investments by forming favorable investment climate, as well as reduction if administrative barriers in construction and update of main funds of housing and communal services. The article proposes methodological bases for assessing the state of the investment climate in the region, as well as the methodology for the formation and evaluation of the investment program of the housing and communal services enterprise. The proposed methodologies are tested on the example of the Voronezh region. Authors also showed the necessity and expediency of using the consulting mechanism in the development of state and non-state investment projects and programs.
\end{abstract}

\section{Introduction}

As the results of statistical studies show, the provision of housing for the population in the regions of Russia remains at an extremely low level, despite a fairly large volume of construction [1]. In addition, housing renovation programs planned and implemented in a number of cities and regions, including in the Voronezh region, are aimed not only at providing affordable housing for the population, but also to ensure that housing meets the requirements of innovation, environmental friendliness, and energy efficiency [2]. Compliance with these requirements, along with ensuring the efficiency of urban development, postulates the need for growth in high-rise construction in the residential structure. Investments attraction at the same time can only be carried out with the formation of a favorable investment climate in the region [3].

The rapid erection and efficient functioning of high-rise buildings depends on many factors and, in particular, on the structure and the degree of renewal of the basic production assets of utilities, which affects not only the possibility of connecting the building to networks [4].

The analysis of the current state of the industry Indicates that the achievement of the conceptual tasks of reforming to improve the effectiveness of this sphere and to ensure the required quality of the services provided is impossible without a well-founded approach to

\footnotetext{
* Corresponding author: belyaeva-sv@mail.ru
} 
the problem of searching for and purposeful use of financial resources for the technical reequipment of enterprises in this sphere.

\section{Materials and Methods}

According to representatives of the construction complex of the Voronezh region, one of the main reasons restraining the tempo of high-rise housing construction is the excessive length of the period for issuing initial permits for construction. Summarizing the results of analyzing the perception of the relative size of administrative barriers by the subjects of the construction market, we can arrange them for operating firms in the following order: problems with real estate (rent and purchase of land and buildings), legal system, regulation (Figure 1).

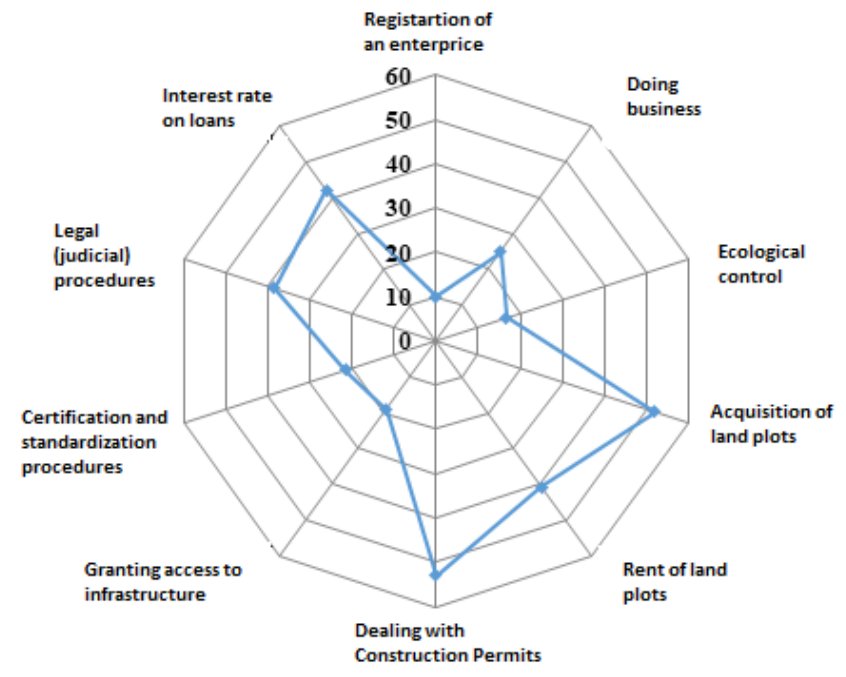

Fig. 1. Assessment of the importance of administrative barriers for the development of construction business

In general, the costs of overcoming administrative barriers by the construction organizations of the Voronezh region are proposed to be determined as follows (Figure 2).

$$
\frac{Z_{\mathrm{rr}}+Z_{\mathrm{n}}}{\frac{\mathrm{Z}_{\mathrm{r}}+\mathrm{Z}_{\mathrm{e}}}{\mathrm{Z}_{\mathrm{l}}+\mathrm{Z}_{\mathrm{p}}+\mathrm{Z}_{\mathrm{reg}}+\mathrm{Z}_{\mathrm{ra}}}}
$$

Fig. 2. The costs of overcoming administrative barriers by construction organizations in the Voronezh region,

where $Z_{\mathrm{vr}}$ - costs which are connected with the loss of management time to resolve issues in connection with the implementation of mandatory requirements and procedures; $\mathrm{Z}_{\mathrm{r}}-$ costs which are connected with tax accounting (expenses for the organization of tax accounting, including reporting); $\mathrm{C}_{\mathrm{ab}}$ - total costs for administrative barriers; $\mathrm{Z}_{\mathrm{r}}$ - regular costs; $\mathrm{Z}_{\mathrm{b}}$ - oneoff costs; $Z_{1}-$ costs connected with participation in CPO; $Z_{p}-$ cost connected with verifications (labor costs + fines and penalties); $Z_{\text {reg- }}$ registration costs (official and unofficial payments); $Z_{\mathrm{ra}}-$ access costs (costs in connection with land and real estate permits) 
Based on the calculations carried out, the costs of overcoming administrative barriers on average in the organizations of the construction complex in the Voronezh Region have decreased over the past few years, but still amounted to about 164.12 thousand rubles.

Thus, despite the existence of state program-targeted measures to provide housing for the population, renovation of housing, the mechanism for implementing appropriate investment programs, both at the federal and regional levels, needs to be clarified and adjusted to overcome the identified shortcomings.

Second key moment is stimulating of investment activity in the region. Certain measures of influence on business environment should be taken to stimulate investment activity in order to form favorable investment climate [5].

We identified key factors of investment potential and risk. In fact, based on the results of the analysis, one can answer the question of what is included in the concept of the investment climate in the region. For a detailed study, two ratings of the region's investment attractiveness were selected: ratings based on the rank of the potential and the rank of risk. These rating contain enough data for economic analysis [6].

Data on factorial loads allow us to formulate conclusions about the relative weight of an individual trait in the structure of the resulting factor. In turn, data on factor weights determine the ranking of objects for each factor.

After the calculations, the objective functions will have the following form:

The objective function of the risk of the investment policy of the region:

$F=0,287 Q_{Z}+0,004 Q_{P}+0,375 Q_{E}+0,474 Q_{F}+0,600 Q_{S}+0,373 Q_{K}+0,006 Q_{E K}(1)$

where $Q_{z}$-- the coefficient of optimum or the rank of legislative risk; $Q_{p}$ - the coefficient of optimum of political risk; $Q_{e}-$ the coefficient of optimum of economic risk; $Q$ $f$ - the coefficient of optimum of financial risk; $Q_{s}-$ the coefficient of optimum of social risk; $Q$ - the coefficient of optimum of criminal risk; $Q_{e k}$ - the coefficient of optimum of ecological risk; $a, b, c, d, e, f, h$ - measures of the influence of determining factors on the resultant, or the magnitude of factor loads.

The objective function of the investment policy potential of the region

$$
F=0,851 Q_{T}+0,916 Q_{P}+0,922 Q_{E}+0,925 Q_{F}+0,888 Q_{I}+0,778 Q_{K}+0,135 Q_{I N}+0,149 Q_{P R}
$$

where $Q_{t}$ - the coefficient of optimum or rank of labor potential; $Q_{p}$ - the coefficient of optimum of consumer potential; $Q_{e}-$ the coefficient of optimum of production potential; $Q_{f}$ - the coefficient of optimum of financial potential; $Q_{i} \quad$ - the coefficient of optimum of institutional potential; $Q_{k}$ - the coefficient of optimum of innovation potential; $Q_{i n}-$ the coefficient of optimum of infrastructure potential; $Q_{p r}$ - the coefficient of optimum of natural resource potential.

In our opinion, some of the indicators are highly correlated and, therefore, are interdependent and replaceable. Therefore, in order to optimize the calculations for a potential investor, we consider it expedient to modify the methodology of RA «Expert» in the following way:

1. We suggest to calculate the investment risk analysis by three components, the tightness of which is maximized with the resulting indicator (social risk, financial risk, economic risk).

2. It is also expedient to calculate the investment potential for three main factors that have the greatest impact on the final potential (financial potential, production potential, consumer potential).

3. It is necessary to add third section to analyzed indicators ""Legislative and Legal Potential of the Region".

Having received a modified methodology for assessing the investment potential of the region and making a recalculation of all indicators, the values of the Spearman correlation coefficient and the determination coefficient remained unchanged. The calculation of the concordance coefficient by components has changed, but the generalizing characteristic has 
remained unchanged. We can assume that the optimization of the method is possible, since the results of calculations are close.

In this case, the objective functions acquired the following form:

Function of risk of investment policy of the region:

$$
F=0,375 Q_{E}+0,474 Q_{F}+0,600 Q_{S}
$$

Function of the investment policy potential of the region:

$$
F=0,916 Q_{P}+0,922 Q_{E}+0,925 Q_{F}
$$

The third key point in reviving the tempo of high-rise housing construction is the need to update the fixed assets of housing and communal services [6]. In order to ensure a sufficient level of quality of services, to maintain productive capacity in working order and to ensure innovative development, the utility company, along with the production program, has the right to form an investment program $[7,8]$.

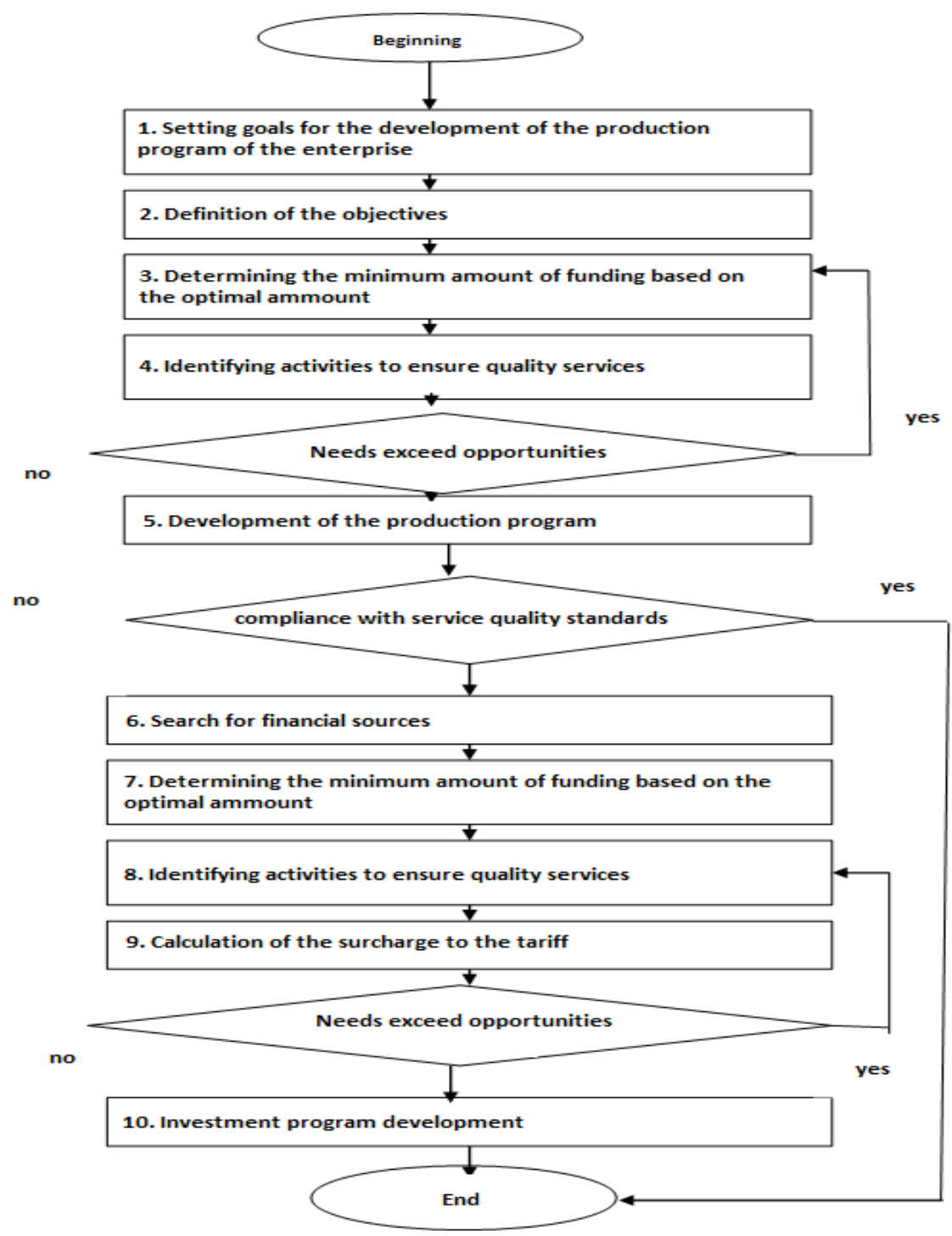

Fig. 3. Investment program development algorithm 
There are no practical recommendations on the formation of investment programs. In this regard, it seems appropriate to take into account regional specifics, to specify the set of requirements, to recommend an algorithm and procedure of the formation of an investment program (Figure 3, 4).

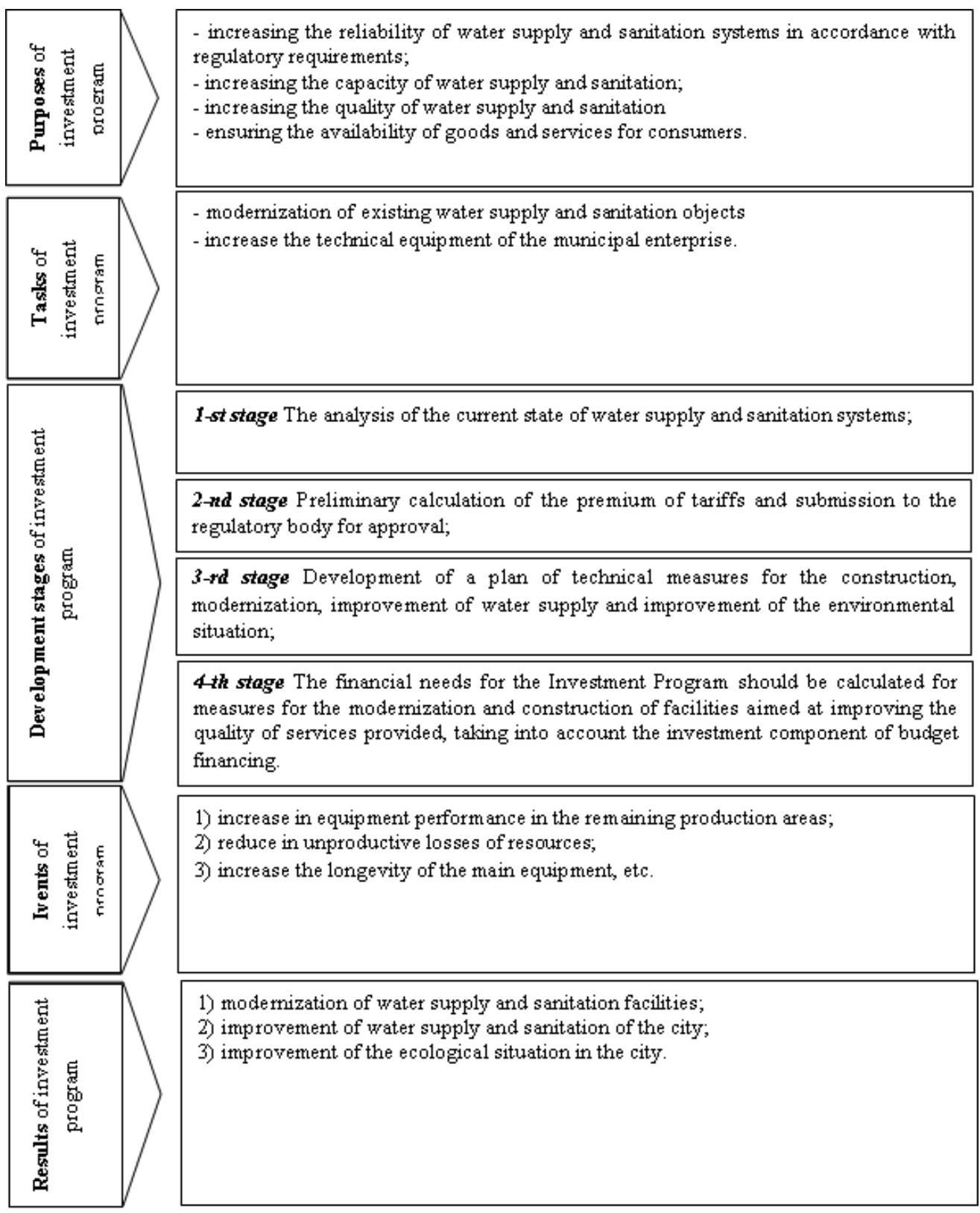

Fig. 4. The procedure for the formation and content of the investment program

To assess the effectiveness of formed investment program, a system of indicators characterizing the increase in the availability of services and the trouble-free operation of fixed assets achieved as a result of the program implementation should be used $[9,10]$. Such indicators should be a characteristic of condition and development of communal 
infrastructure systems, operating conditions and parameters that are accessible to observation and measurement, providing the required level of quality. They can be used not only to estimate the reliability, balance of systems of communal infrastructure, the availability of services for customers, but also to provide ecological requirements and the quality of services provided.

\section{Results}

Based on the obtained methodology, an analysis of the investment attractiveness of the regions of the Central Federal District was made. Among the regions of the Central Federal District Voronezh takes the third place by the availability of investment potential and the sixteenth (from 18 regions) by the riskiness of investments in this area. As a result, the overall rank of investment attractiveness is quite high.

With regard to assessing the effectiveness of investment programs of housing and communal enterprises, we propose the following system of indicators (Table 1).

Table 1. Recommended composition and characteristics of the assessment of the investment program of the utility (fragment)

\begin{tabular}{|c|c|}
\hline Indicator & Characteristics and calculation procedure \\
\hline \multicolumn{2}{|r|}{ 1. RELIABILITY } \\
\hline $\begin{array}{l}1.1 \text { Increasing the } \\
\text { reliability of fixed assets }\end{array}$ & $\begin{array}{l}\text { Reduction in the number of consumer complaints registered during } \\
\text { the year. }\end{array}$ \\
\hline 1.2 Accident rate & $\begin{array}{l}\text { The ratio of the number of accidents recorded during the year to the } \\
\text { total length of the network. }\end{array}$ \\
\hline $\begin{array}{l}\text { 1.3 Average time to } \\
\text { eliminate accidents }\end{array}$ & $\begin{array}{l}\text { The ratio of the total duration (time) expended in eliminating } \\
\text { accidents during the year to their number. }\end{array}$ \\
\hline 1.4 Resource volume & $\begin{array}{l}\text { The dynamics of the resource volume is shown in terms of the } \\
\text { following parameters: useful leave (including the population and } \\
\text { other consumers), losses, resource consumption for own needs. }\end{array}$ \\
\hline $\begin{array}{l}1.5 \text { Movement of fixed } \\
\text { assets }\end{array}$ & $\begin{array}{l}\text { Indicators of the movement of fixed assets: the coefficients of } \\
\text { renewal, wear, fitness, retirement, and the average wear factor } \\
\text { should be estimated for all fixed assets and by groups of funds, } \\
\text { including separately for networks }\end{array}$ \\
\hline
\end{tabular}

Formation of investment programs based on the proposed provisions will increase the efficiency of municipal enterprises and improve the quality of services.

\section{Discussions}

In our opinion, one of the possible methods of activating the tempos of high-rise housing construction, which contributes to the optimization of state and non-state investment programs, is the use of management consulting as construction enterprises and housing and communal services enterprises (as a rule, on the examination of operational and tactical business improvements, which are less costly, but they give visible results in a relatively short time), and government authorities (on territories, on which there are no shortage of funds, as well as problematic municipalities, which are trying to form a long-term plan to overcome the crisis). With the use of consulting tools, it is possible to develop program measures to improve the investment climate in the region, as well as investment programs to improve the efficiency of the housing and communal services in the region, which, in our opinion, will contribute to a more dynamic development of high-rise housing construction in the region. 
The close cooperation of a team of consultants, expert analysts and officials on projects of state and municipal importance, including public-private partnership, will further promote the improvement of life in regions and municipalities, and will also promote the development of consulting itself. Particularly important areas of such consulting in the future will be: the development and examination of concepts, strategies, programs of sectoral, municipal and regional social and economic development, territo rial marketing and regional branding, structural reorganization of complexes, industries and enterprises, preparation of projects to justify attracting private investments in programs development of housing and communal services and high-rise construction [11].

\section{Conclusion}

To improve the investment climate further, it is necessary to influence the identified key components of investment potential and risk in the region, in particular, the formation of the opportunity to implement projects in the high-rise construction segment, reduce administrative barriers, grant additional tax benefits and preferences.

There is a number of problem areas in the implementation of program activities, including insufficient attraction of extra budgetary sources of funding, lack of concentration of allocations for key problems, shortcomings in consolidating budgetary allocations at various levels, and in the system of goal-setting and responsibility. The development of measures aimed at overcoming shortcomings contributes to an even more dynamic growth in the effectiveness of state and non-state investment programs at all levels, including unstable economic environment. We consider it appropriate to develop such events, with the involvement of professional consultants in this area of consulting.

\section{References}

1. A. Ohotina, O.Lavrinenko. Procedia - Social and Behavioral Sciences, 174, (2015)

2. N.A. Anisimova, V.G. Popov, T.I. Smotrova Planning and evaluation of the effectiveness of measures for advertising and promotion in the residential real estate market. Modern economy: problems and solutions. 2 (86). P. 96-106. (2017)

3. P.M. Belmiro Duarte, M.C. Nuno Oliveira, O. Lino Santos Dynamics of quality improvement programs. Optimal investment policies. Computers \& Industrial Engineering, 91, (2016)

4. D. Dollar, M. Hallward-Driemeier, T. Mengistae. World Development, 34( 9), (2006)

5. V.S. Kankhva, S.S. Uvarova, S.V. Belyaeva Procedia Engineering. 165. (2016)

6. Y Kolyhaeva Procedia - Social and Behavioral Sciences, Volume 166, (2015)

7. A. Larionov, E. Nezhnikova Role of energy efficiency in improving the quality of housing projects 2016 International Journal of Applied Engineering Research. - №6.

8. N. Bayraktar, Procedia Economics and Finance, 5, (2013)

9. T. Hayes, F. Murtinho, H. Wolff World Development, 93, (2017)

10. R. Bril, O. Kalinina, I. Ilin, MATEC Web of Conf. 106, 08010 (2017) DOi 10.1051/matecconf/201710608010

11. I.V. Ilin, A.B. Anisiforov, Improving the efficiency of projects of industrial cluster innovative development based on enterprise architecture model, WSEAS Transactions on Business and Economics, 11, pp 757-764 (2014) 